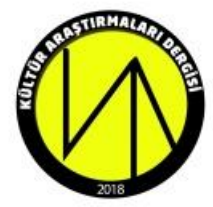

\title{
KORONAVIRÜS PANDEMISININ KÜLTÜRE ETKILERI
}

\author{
Effects of Coronavirus Pandemic on Culture
}

Filiz GÜVEN*

\section{ÖZET}

Topluluktan topluluğa göre karmaşık bir yapı arz eden kültürel davranışlar, kişinin geleneksel bir formda gerçekleştirdiği bir eylem olması yönüyle toplumların ve milletlerin şekillenmesindeki en önemli etkenlerden biridir. Bireyin atasıyla bağını vurgulamak üzere kullanılan kültür kavramı, geleneksel yaşamdan modern yaşama geçişle birlikte değişmeye başlayan toplumsallık kavramı sonrası yeniden gündeme alınmıştır. Özellikle 19. yüzyılda milletlerin köken arayışı ve kökenin kültür içindeki gizemi, antropoloji, halk bilimi gibi sosyal bilimlerin ilgi odağı haline dönüşmüştür. Teknolojinin gelişmesi ile toplumsallıktan bireyselliğe geçişin en önemli aşamalarından biri olan yirminci yüzyıl yeni sosyal yaşamın şekillendiği, yeni iletişim yöntemlerinin geliştiği bir dönemi kapsamaktadır. Iletişim teknolojisinde yaşanan bu değişim, dünyayı birbirinden haberdar bireylerin yaşadığı bir yer haline dönüştürürken gelişimini geç tamamlayan ya da tamamlamayan ülkeler; sözlü, yazılı ve elektronik kültürün iç içe geçtiği bir kompleks yaşama sahip olmak durumunda kalmıştır. Bu süreç beraberinde yeni problemleri ve bu problemlere yönelik yeni çözümleri gündeme getirmiştir. Tüm bu kavram ve yaşam biçimlerindeki karmaşa nedeniyle kültürel öğelerin yerini yeni bir yapıya bıraktığı ve dolayısıyla binlerce yıldan beri getirilen ancak yeni şartlar nedeniyle kısa sürede unutulmaya yüz tutan kültürel öğeleri, korunma ve geleceğe aktarma konusu, genelde sosyal bilimlerin özelde halk bilimin sıklıkla dile getirdiği başlıklardan biri haline dönüşmüştür. Bu kapsamda çalışma, Covid-19 sürecinin sosyokültürel etkilerini, eski ve yeni kültürlerin mayalanma şeklini, sürecin devam etmesi durumunda değişebilmesi muhtemel kültürel davranışları, kültür-kimlik kavramları etrafında irdelemektedir. Bu noktada çalışmanın temel çıkış noktası, kültürel davranışları canlandırma amacıyla yapılan girişimlerin bir noktadan sonra amaçtan uzaklaşması, popüler olması öte yandan kültürün canlanmasının ihtiyaç merkezli olmakla birlikte bağlamdan bağımsız olmadığı görüşüdür.

Anahtar Sözcükler: Covid-19, SOKÜM, Kültürel Miras, Kültürel Bellek, Kimlik.

\footnotetext{
* Dr. Öğr. Üyesi. Sinop Üniversitesi, Fen Edebiyat Fakültesi, Türk Dili ve Edebiyatı Bölümü, Sinop/Türkiye. E-posta: filiz__guven@hotmail.com. ORCID ID: 0000-0002-9123-929X. 


\section{ABSTRACT}

Cultural behaviors that present a complicated structure from one community to another are one of the important factors in shaping societies and nations in the sense that it is an action performed in a traditional form by an individual. The concept of culture which is used to emphasize the individual's bond with his/her ancestor is once again brought up after the concept of socialization that started to change with the transition from traditional life to modern life. Root-seeking of nations and the mystery of the root in culture have become the center of interest of social sciences like anthropology and folklore especially in $19^{\text {th }}$ century. $20^{\text {th }}$ century, which is one of the most important phases of the transition from socialization to individualism with the development of technology, covers a period in which a new social life is shaped, and new communication methods are developed. While this change in communication technology turns the world into a place where individuals being aware of each other live, the countries, which complete their development late or do not complete, are in the position of having a complicated life in which oral, written and electronic cultures are intertwined. This process has brought up new problems and new solutions towards these problems. The issue of preserving and transferring cultural elements, which have been replaced by a new structure due to the confusion in all these concepts and lifestyles and therefore, which have been introduced for thousands of years but have been forgotten in a short time due to new conditions, is one of the topics that mostly social sciences in particular folklore mention. In this context, the study examines the sociocultural effects of Covid-19 process, the aggregation of old and new cultures, cultural behaviors that are likely to change in the case of continuation of the process as part of culture- identity concepts. At this point, the main starting point of the study is the view that the attempts which have been made to revive the cultural behaviors stray away from the purpose after a certain point and become popular, but on the other hand the revival of culture is need-centered but not context-independent.

Keywords: Covid-19, ICH, Cultural Heritage, Cultural Memory, Identity.

\section{Giriş}

Sağlık sorunlarını anlama, çözümleme ve daha uzun yaşama ideali tüm zamanların en önemli meselelerinden biri olmuş, hem bireysel hem de toplumsal düzeyde, uzun yaşama ideali insanları bilimsel anlamda önemli noktalara taşımıştır. Ancak sağlık sorunları bazı dönemlerde bireysel alandan çıkarak bütün insanlığı tehdit eden bir salgına dönüşebilmektedir. Tarihin birçok döneminde salgın hastalıklarla karşı karşıya kalınmasına rağmen ulaşım imkânlarının bugünkü kadar gelişmemesi nedeniyle salgınların yayılım hızı oldukça yavaş seyretmiştir. Özellikle 1800'lü yıllardan sonra, önemli bir sorun haline gelen bulaşıcı hastalık ve salgınların 
toplumda yarattığı duygu hem bilimsel anlamda hem de toplumsal anlamda dünya milletlerini etkisi altına almış, bir yandan toplulukları birlikte hareket etmeye iterken öte yandan her topluluğun ihtiyaçlarını ilk etapta kendi bildiği geleneksel metotlarla gidermesine neden olmuştur. Bilimsel manada mecburi bir etkileşime sürüklenen milletler, insanlığın ortak sorununa ortak tepkiler verirken; pandemilerde insanlığın tek etkilendiği alan, sağlık ya da ekonomi olmamış, birey veya toplulukların sosyokültürel davranışları da etkilenmiştir.

Salgın döneminde kullanılan yöntemlerin başında epidemi eğrisini yassıltmak gelmektedir. Böylece salgın yayılım zirvesini erteleyip zayıflatarak sağlık sistemine aşırı yüklenme önlenmiş, aşı ve tedavi geliştirilmesi için zaman kazanılmış olur. Ek olarak temizlik, maske kullanımı, bireysel karantina gibi kişisel önlemler; uzaktan eğitime geçilme ve toplu etkinliklerin iptal edilmesi, kamuda mesai yükünün ve tüm sektörlerde iş hareketliliğinin azaltılması gibi toplumsal tedbirler; sosyal alanlardaki yüzeylerin temizlenmesi gibi çevresel önlemler ile virüsün yayılması yavaşlatılmaya ve kontrol altında tutulmaya çalışılır (Aslan, 2020: 39). Alınan bu önlemler hemen hemen bütün salgın hastalıklar için geçerli olmakla birlikte, bu süreç sonrası birey ya da topluluk yeni bir yaşam tarzı ile karşı karşıya kalacağı için yaşamın belli alanlarında değişimin yaşanması muhtemeldir. Ancak burada ilk belirtilmesi gereken, yaşanması muhtemel değişimin salgın hastalığın süresiyle ilgili olduğudur. Eğer süre uzarsa, bu dönemde kazanılan davranışların kalıcı olma ihtimali artar. Öte yandan sürenin uzayıp uzamamasına bağlı olmaksızın gelişecek ya da geliştirilmesi gereken tepkilerin başında, insanlığın bu ve benzeri durumla tekrar karşı karşıya kalması halinde bundan sonraki adımların belirlenmesidir.

Covid-19, dünya genelinde yaşayan tüm insanların sağlığını tehdit eden bir bulaşıcı hastalık olması nedeniyle Dünya Sağlık Örgütü tarafından pandemi olarak ilan edilmiş, dolayısıyla etkisini ulusal ve uluslararası ekonomide hemen, diğer birçok alanda ise süreç içerisinde hissettirmiş ve hissettirecek bir salgın hastalık olarak kabul edilebilir. Pandemi döneminde üretim ve tüketim ilişkilerinde yaşanan değişim, hem bireyi hem de bağlı bulunduğu topluluğu yeni yaşam tarzıyla karşı karşıya bırakmakta ve yakın gelecekte oluşabilecek kültürel değişim hakkında araştırmacılara fikir vermektedir. Öngörülen değişimin boyutunun yalnızca meta düzeyinde kalmayacağı özellikle kültürel/sosyal hayat ve buna bağlı tüm ilişkilerin süreçten etkileneceği savlanmaktadır. Ancak bu sav, sadece pandeminin sonucu hakkında bir tartışma alanı açmamakta, aynı zamanda insanlığın henüz üstesinden gelemediği gelecek kaygısı ve onunla ilgili be- 
lirleyeceği istikametin yönü hakkında da bir tartışma açmaktadır. Her şeyden önce insanoğlu, -ilkel insan korkusu kadar olmasa da- hayatta kalma korkusunu tam olarak alt edemediğini bir kez daha deneyimlemek zorunda kalmıştır ki bu daha üst düzeyde bir duygudur._Pandemiyle birlikte_yaşamın, bilinçli bir tavır ile organize edilmesi gerektiği bir kez daha deneyimlenmiştir. Ancak bu çalışmanın ana çerçevesini, pandemi döneminde sağlık, ekonomi ya da ticari alanlarda verilen tepkilerden ya da alınan önlemlerden ziyade, bu tepkilerin yakın ve uzun vadede yaşanan ve değişmesi muhtemel kültürel alışkanlıklara yansıması oluşturmaktadır. Bu noktada, ilk olarak değinilmesi gereken pandeminin sosyal ilişkiler üzerindeki etkisinin, sözden yazıya geçişi hatırlatan bir değişim içerdiğidir. Örneğin sözlü iletişim; kişiliği belli açılardan daha az içine kapalı, dış dünyaya ve topluma daha açık kılarken insanları birleştirir ama yazı ve okuma kişinin tek başına yaptığı ve kendi iç dünyasına döndüğü eylemlerden oluştuğu için (Ong, 2018: 87) belli durumlarda kişiyi yalnızlaştırmaktadır. Hâkimiyetin zorlaştığı birinci sözlü kültüre kıyasla yazılı kültür, kontrolün sağlandığı bir alanı oluşturmakta ve bireyi yalnızlaştırmakta, öte yandan elektronik kültür çağı ile bilinç seviyesi farklı bir duruma taşınmakta, yazının ve sözün iç içe kullanıldığı aynı zamanda görsel-işitsel öğelerle desteklendiği yeni bir yapı oluşmaktadır. Bağlantıda yaşanan değişim, etkileşim biçimini dolayısıyla kültürü değiştirmektedir. Bahsedilenler çerçevesinde dünyanın elektronik ağlarla birbirine bağlanması, insanlık için yeni bir kültürel yayılım alanının oluştururken (Kızıldağ, 2016: 456) gelişimin bundan sonraki aşaması merak konusu olmuştur. Burada anlatılmaya çalışılan şey, sözlü edimler ya da yazılı metinler değil, pandemi sürecinde geliştirilen davranışların ve pandemiyle birlikte artan teknoloji ihtiyacının pandemi sonrası değişmesi muhtemel kültürel yapıyla ilişkisinin istikametidir.

\section{Kültürel Süreklilik, Kültürü Koruma ve Canlandırma}

Endüstrileşme süreci sonrası teknoloji, insanlığı inorganik seçeneklerin fazla, emeğin ve iş gücünün az olduğu yeni bir kültür dairesi içine sürüklemiştir. Kültürel sermaye açısından insanlığın tekelleştirilmesi (Demir, 2018: 3784) sözlü ve yazılı kültürün aksine teknolojik bağlantı sistemleriyle toplumsal ve kültürel değerleri belli noktalarda etki altına almış ve geleneğin dokusunu etkilemeye başlamıştır. Teknolojik gelişmeler öncelikle emek tanımlarını ve değerlendirmelerini, dolayısıyla iş merkezli kültürel yaşam biçimlerini değiştirmektedir (Özdemir, 2019: 208). Özellikle günlük hayatın farklı bir seviyede yaşanması üretme ve tüketme alışkanlıklarında yaşanan dönüşüm, "şey”lerin var olma amacının sorgulanmasına neden 
olmakta ve var olan "şey"in faydalı olması gerektiği üzerine bir çeşit yenidünya görüşü oluşturmaktadır. Bu görüşte bir "şey"in sadece var olmak adına varlık göstermesine izin verilmemiş, faydacılığın değersiz bulduğu her "şey" devre dışı bırakılmıştır (Eagleton, 2019: 103). Gelişen yeni düzene karşın farklı değerlerin ve anlam arayışlarının meydana gelmesi, on dokuzuncu yüzyıl kültür çalışmalarının temel paradigması olan kültürlerin yok olma tehlikesi ve medeniyetler arası farkın kalmaması kültürü, küreselleşmeye karşı koruma içtepileri olarak sonuçlanmıştır. Bunun nedeni, hızla değişen dünyada kimlik etrafında şekillenen ve kendi içerisinde birden fazla sosyal gerçekliğe gönderme yapan yapının birtakım farklılıklar sonucunda değişime uğrayacağı düşüncesidir. Bu anlamda geleneği korumak ve yaşatmak aynı zamanda kimliği korumak olarak değerlendirilmiş ve alınan önlemler ve çalışmalar bu kapsamda yapılmıştır. Özellikle yirminci yüzyılın son çeyreğinde tartışılan "kültürü koruma" düşüncesi sonrası, konuyla ilgili dört sözleşme ortaya çıkmıştır (Oğuz, 2018: 42). Anlaşma kapsamında, UNESCO dünyanın bütün bölgelerinde geleneksel kültüre ve bunun seçkin örneklerine karşı bir duyarlıık oluşturmayı amaçlamış, toplumların koruma bilinci yükseltilmeye çalışılmıştır (Oğuz, 2018: 42).

Kültürel olanı korumaya dönük tepkilerin oluşum biçimleri önemlidir. Temelde basit bir içgüdü ya da sığ bir girişim olmamakla birlikte, atılmış bütün adımlar amaca ulaşma noktasında belli aşamalarda yeterli değildir. Geleneklerin, toplumsal uygulamaların ve diğer her türlü kültürel öğenin korunması, yaşatılması ve canlandırılması kapsamında gerçekleştirilen bu çalışmalar, kültürel öğelerin sergilendiği bir müze, kısıtlı zamanlarda dâhil olunan bir ritüel, müzede cam korumanın arkasından görülen bir kültürel simge kendi içinde kültürü koruma, canlandırma ve gelecek kuşaklara aktarma noktasında değerlendirilmelidir. Nitekim tüm bunlar, kültürel değerleri yaşatma ve koruma noktasında önemli girişimler olsa da asıl sorgulanması gereken, bu tür davranışların kültür endüstrisi, küreselleşme ve popüler yaklaşımlarla olan bağıdır.

Yukarıda belirtilenlerden hareketle kültürel süreklilik bazı noktalarda onu canlandırma ve koruma çalışmalarından kesin biçimde ayrılmaktadır. Koruma ve canlandırma bir çeşit seçime tabi olmakla beraber bürokrasiye ve resmî ideolojiye göre geliştirilmiş popüler yaklaşımlar sonucunda oluşabilmektedir. Öte yandan bir kültürel davranışın kendi başına varlık göstermesi ve belli alanlarda devam etmesi, ihtiyaca bağlı gelişen bir durum olarak değerlendirilmelidir. Buradan hareketle kültür üretimi, biyolojik, fizyolojik bazı durumları da çağrıştırmaktadır. Eğer böyle ise, kültürel tep- 
kinin her bir dürtüyle ilgili yaşamsal süreci topluca belirlediği ve şekillendirdiği söylenebilir (Malinowski, 2016: 91). Bu, sadece kültürün oluşum biçimiyle ilgili bir süreç olmayıp aynı zamanda onun canlandırma ve hayatta kalma biçimiyle ilgili de bilgi vermektedir. Ancak kültür oluşumunun ihtiyaç ile olan ilişkisi herhangi bir kültürel davranışın bağlam ile olan ilişkisini arka plana itmemelidir. Daha önce de değinildiği üzere bir kültürel davranışın devam etmesi öncelikle ihtiyaca cevap vermesi ile ilgili olsa da ikinci önemli şey, onun yaşatılmaya çalışılan döneme -kültürel yapıyauygun olup olmadığıyla ilgilidir. Nitekim bağlamından kopuk ya da insan ihtiyacından uzak bir kültürel öğenin uzun süre varlık göstermesi pek de mümkün değildir.

Covid-19 sürecinde dünyanın dramatik bir biçimde sosyal izolasyona maruz kalması, salgının bu şekilde kontrol altına alınmaya çalışılması, insan imalatı olan ve uygarlaşmanın en önemli adımı olan endüstrileşmeyi ve beraberindeki birçok alanı insanlığın hizmetinden belli noktalarda uzaklaştırmasına rağmen belli noktalarda daha da işlevsel hale getirmiştir. Covid-19 sonrası insanların yaşam ve tüketim alışkanlıklarının değişmesi bazı ürünlerin satışlarını etkilemeye başlamıştır. Bir internet haberinde (URL1) perakende teknoloji şirketi Stackline'nin yaptığı araştırma sonuçları paylaşılmış ve bu sonuçlara göre satışı en çok yapılan birinci ürün tek kullanımlık eldiven, ikinci ürün, ekmek yapma makinesi, ardından ise kurutulmuş baklagiller gelmektedir. Sonrasında sırayı günlük intiyaçlara göre temizlik eşyaları, spor ekipmanları, bilgisayar ve bilgisayar aparatları almaktadır. Satışı azalan ürünlerdeki genel görünüm temel gereksinimlerin dışında seyahat ile ilgili ürünlerden oluşmaktadır. Ürünlerde yaşanan artış ve azalış, intiyaç aşamaları bakımından incelendiğinde ilk olarak dikkat edilmesi gereken, insanlığın karşı karşıya kaldığı tehdidin cinsine göre öncelikli olarak birincil intiyaçların karşılandığıdır. Bu manada, bireyin metabolik gereksinimlerini gidermek dış dünyayla kurduğu bağ, beslenme kültürüyle alakalı bir çeşit tepkiyle sonuçlanmaktadır. Bu tepkide toplumsal koşullara göre hareket etme mantığının yanı sıra insanların kendi ihtiyaçlarını kendi bildikleri şekilde giderme refleksi bulunmaktadır.

Sosyal izolasyon sonucu evde kalan insanların birçoğu ekmek, yemek yapımında geleneksel tercihlerde bulunmuş, bu süreçte kültürel öğeler, kendine hem uygulama hem de aktarma alanı bulmuştur. Aynı ev içerisinde annesinden veya babasından ekmek yapımını öğrenen bir genç, kültürel bir davranışın bundan sonraki uygulayıcısı ve aktarıcısı konumuna gelmiştir. Bir diğer örnek ise, özellikle yoğun iş temposu ile kent merkezinde yaşayan insanların kazan yemeği adı verilen yemek kültüründen uzaklaş- 
ması ve hazır gıdalara yönelmesi yine süreç içerisinde faklı bir boyuta taşınmıştır. Yeme alışkanlığında hem hijyen koşulları hem alt ve orta gelirli aileler için daha ekonomik olması nedeniyle kazan yemeğine dönülmüş ve geleneksel yemek tarifleri yine usta-çırak ilişkisi içerisinde canlandırılmış ve bir sonraki kuşağa aktarılmıştır. Ancak kültürel canlanma sadece ekmek ve yemek kültüründe yaşanmamış, diğer birçok alanda da yaşanmıştır. Gerek sözlü ürünleri gerek geleneksel roller, aile kurumunun yeniden güçlenmesi ve geleneksel oyunlar gibi birçok alanda kültürel mayalanma süreci başlamıştır. Durumun mecburiyetle olan ilişkisi düşünüldüğünde, kültürel canlanmanın hem kalıcılık süresi hem de sebebi anlaşılabilir.

Bu bağlamda, durumun iki önemli sonucu tartışılabilir. Birincisi, kültürel canlanmanın aktif olarak görüldüğü; ikincisi ise yeni bir kültürel yapının oluşumuna dair sürecin başladığıdır. Ancak kültürel pratiklerde yaşanan canlanma, hayatın normale dönmesi sonrasında özellikle sözlü kültür ürünleri özelinde unutulması ve eskiye dönülmesi muhtemelken yemek ve ekmek kültüründe yaşanan hareketliliğin devam etmesi - diğerine oranladaha güçlü bir durumdur. Kaldı ki uygulamaya dayalı yaşanan canlanma devam etmese dahi öğrenme eylemine bağlı olarak yaşanan süreç, bir çeşit deneyim alanı açtığı için kalıcılığı sözlü edimlere göre daha uzun olacaktır. Öte yandan, yemek ve ekmek üretiminde yaşanan canlılık değerlendirildiğinde, kültürel süreklilik ve gelenek üzerine kurulacak tartışmada, tartışmanın geleneğin bağlayıcı rolü üzerine değil, hangi durumlarda veya nasıl canlandığı/canlandırılabileceği üzerine kurulu olması gerekmektedir. Belirtilenler doğrultusunda; bir kültürel simgeyi müzeleştirmek veya herhangi bir şekilde yaşamsal olanla iç içe varlık gösteremeyen bir öğeyi koruma altına almak, kültürün canlılığına ve sürekliliğine hangi boyutlarda katkı sağlıyor, değerlendirilmelidir.

Bu değerlendirmede canlının yaşamını devam ettirme biçimi ve bunun mevcut koşullarla ilişkisi göz önüne bulundurulmalı ve kültürel sürekliliğin intiyaç ve bağlam ile olan ilişkisi dikkate alınmalıdır. Ekmek yapılır ama fırın açıksa bu intiyaç oradan giderilir. Bu davranıştaki basit koşullanma, olayın teknoloji çağıyla ilgisini ortaya koyarken gündelik yaşamın akışıyla ilgili de bilgi vermektedir. Hemen her bireyin iş dünyasına dâhil olduğu düşünüldüğünde, bugünün daha önceki zamanlardan farkı, cinsiyetler arası iş bölümünün artması, ampirik bilginin yükselmesi, yaşamın hızlı ve yoğun akması, bireyi intiyaçlarını giderme noktasında işlevsel ve pratik olana yöneltmiş ve bu yönelim zamanla alışkanlığa dönüşmüştür. Dolayısıyla kültür değişmeleri, değişim ve dönüşüm dinamiklerinin bağlantılı olduğu durumlarla ilgilidir. 


\section{Covid 19 Pandemisinin Bugüne ve ileriye Dönük Kültürel Etkileri}

Pandeminin insan davranışı açısından ortaya çıkardığı ilk durum, sosyal hayatta yaşanan değişimin seçim değil zorunluluk olmasıdır. Dolayısıyla süreçte geliştirilen bütün davranışlar serbest bir seçime tabi olmadığı gibi ne tamamıyla yerel ne de tamamıyla küresel bir görünüm sergilemektedir. Elbette mesele dillendirildiği kadar basit değildir. Davranışın bir seçime tabi olmaması, popüler bir tavır sonrası benimsenmemesi ve zorunluluk içermesi, pandemi sürecinin uzamasıyla birlikte diğer birçok alanda olduğu gibi kültür özelinde de bir değişimin başlamasına olanak tanıyacaktır. Sosyal izolasyona bağlı olarak yaşanan ve insanların başta hijyen kaygısı nedeniyle geliştirdikleri "sosyal mesafe", "evde kalma", "uzaktan çalışma", gibi bazı somut adımlar sonrası "yeni normal" ifadesi oluşmuştur. Yeni normal ile kast edilen yaşamın pandemi dönemindeki akış seyri olsa da sürecin devam etmesi, yeni bir kültürel bağlamın da habercisi olarak görülmelidir. Bahsedilen çerçevede, ekonomi, eğitim, iş ve sosyal hayatın işleyişinde yeni davranış modelleri geliştirilmiş ve geliştirilmeye devam etmektedir. Yeni davranışlar beraberinde bu alanlarda oluşturulmuş kültürel yapıyı etkileyeceği için önemlidir. Nitekim yaşam alanlarının farklılaşması kültürün değişimi/dönüşümü için önemli bir unsur olarak kabul görür (Özdemir, 2019: 2019).

Pandeminin kültür üzerinde yarattığı yeni durum, akademide şu ana kadar özellikle sanayi devrimi ve bilgi çağı merkezli olarak ifade edilen kültürün tek tipleşmesi, evrensel kültür ya da tek tipleşme şeklindeki söylemlerin dışında bir tavrı doğurmuş olmasıdır. Değiş̧ime yönelik yapılan tanımlamalarda değişimin bir durumdan yeni bir duruma geçişi ifade eden bir kavram olduğu ve onu meydana getiren toplumsal ve bireysel unsurların varlığı vurgulanırken değişimin bireysel ve toplumsal planda görünür ve hissedilir etkileri olduğu belirtilir (Doğan, 2011: 350). Değişimin toplumsal boyutunu şekillendiren temel etken ise son yüzyıllarda özellikle sanayi devrimi olarak gösterilmektedir. Sanayi devrimine kadar insanlık tarihi, genel anlamda tarım toplumu olarak adlandırılan bir devrin içinde bulunmuş ve sözlü kültür en önemli aktarım aracı olarak kabul görmüştür. Bu sürecin tamamlanmasının ardından ortaya çıkan sanayi devrimi, kullanılan teknik araçlar, sosyal ve siyasal kabullerin değişimine yol açmıştır. ilerleyen süreçlerde gelişmişlik kavramı üzerinden kültür, kültür aktarımının boyutu ve kültürel olanın hangi şekillerde, nasıl devam ettirileceği soruları bir gündem yaratmıştır. Sanayi toplumu sonrasında ortaya çıkan bilgi toplumunda gelişimin evrelerine paralel olarak imalat sanayisinin yerini bilgi endüstrisinin alması, maddi üretim gücü yerine bilgi üretim 
gücünün gelmesi bu dönemin en belirgin özelliklerindendir (Özdemir, 2011: 89).

Sanayileşme ve bilgi çağı, toplumsal değişmeyi şekillendiren kültür, demografik ve fiziki çevrenin değişimi, küreselleşme, göç, teknolojik ve bilimsel gelişme ile kitle iletişim teknolojilerindeki ilerlemeler gibi birçok etkene bağlı olarak hem yerel hem de küresel düzeyde toplumsal yapının birçok alanında etkili olmaktadır (Yeşildal, 2012: 55-57). İnsanlık tarihinin bu yöndeki akış çizgisi, "Günümüz dünyasının gelişme ve değişme seyrinin "küreselleşme" kavramı etrafında gerçekleştiği açıktır. Küreselleşme "bir şeyi dünya ölçeğinde kılmak" ve "bizde olanı dünyaya vermek, başkalarında olanı almak" gibi anlamlar içerse de "alma-verme" dengesinin baskın taraflara ilişkin kültürel değerler üzerinde "tek-tipleşme"ye doğru gittiği açıktır” (Oğuz, 2001: 6). Ancak kültür değişmelerine neden olan dış dinamiklerinin başında yer alan teknoloji faktörü (Özdemir, 2019: 207) pandemi döneminde hem belirtilen şekilde hem de tersi yönde bir değişim içerisine girmiştir. Düşünce detaylandırıırsa, bilgi endüstrisi, internet ve sosyal medya sunumlarının tek tip insan yaratımına karşın pandemi, bahsedilen tek tipleşmenin önüne belli noktalarda geçmiştir. Sosyalliğin ve toplumsallığın pandemiyle birlikte sınırlandırılması ve yaşamın evde geçmesi küresel ekonomik döngünün belli alanlarda sürdürülmesine ve geleneksel bilginin bir nebze de olsa ön plana çıkarak yeniden kendine yer açmasına imkân sağlamıştır. Yukarıda bahsedilen ve temelde kültürlerin canlanması anlamına gelen kültürel mayalanma buna bir örnektir. Dolayısıyla yaşamsal kaygıların ön plana çıkması, bazı alanlarda gelenekle örtüşen yeni bir kültürel yapının doğmasına fırsat sunmuştur. Ancak olayın bu yanı kültüre ilişkin şu ana kadar yapılmış söylemleri belli noktalarda farklılaştırsa da kültürel davranışların seyrine yeni bir tartışma alanı açmaktadır. Belirtilen çerçevede, pandeminin kültürle ilgili boyutu birkaç farklı durumu ortaya çıkarmaktadır. Birincisi, kültürlerin canlanması ve hayatta kalması başlığı altında değerlendirilen ilk durumdur. Bu bölümde özellikle vurgulanmak istenen küreselleşme hızında belli oranda yaşanan yavaşlamaya koşut olarak kültürlerin içe dönmesidir. îkincisi, sosyal izolasyonun kimlik üzerinde yaratacağı tahribattır. Üçüncüsü ise pandemi döneminde edinilen yeni alışkanlıkların bundan sonraki süreçte kitlelerin hayatında yaratacağı etki ve onun yeni bir kültür çağıyla olan ilişkisidir.

Yeni normal kavramı hem bireye hem de dâhil olduğu kültürel yapıya yeni yaşam tarzı önermektedir. Pandemi, sağlık alanında küresel bir kriz olsa da alınan önlemler ve bu önlemlere verilen tepkiler bakımından kimi zaman kültürel davranış farklılıkları içermektedir. Örneğin, ingiltere gibi 
bazı ülkeler, insanları lokantalara çekebilmek adına yeni kolaylıklar sağlamaya çalışırken Türkiye'de AVM girişlerinde görülen insan yoğunluğu yaşanması, ya da Almanya gibi birçok ülkenin Türkiye'ye turist girişini uzun bir süre askıya almasına rağmen, yerli turistin virüse aldırmaksızın yaptığı kumsal keyfi, temelde insan davranışlarının, kültürel edimlerle olan ilişkisini göstermekle birlikte, ülkelerin sosyo-ekonomik durumlarıla ve hükümetlerin politikasıyla da yakından ilgilidir. Ancak çalışmanın temel sorusu, toplulukların bu süreci nasıl yönettiği, sürece verilen tepkiler ya da alınan önlemler olmadığından bu örneklendirmelerin asıl amacı da farklı kültürlere ait davranış biçimlerinin -sürecin devam etmesi durumunda- kültürel davranış biçimleri üzerindeki etkisini göstermektir. Özellikle Türkiye gibi nüfusunun büyük bölümünün kent kültüründen uzak, periferi/kırsalda yaşayan ve tarımla uğraşan ülkeler; sanayi ve teknoloji alanında gelişmiş ülkelere kıyasla modern yaşamın getirdiği yalnızlaşma sürecine tam olarak dâhil olmamıştır. Bu açıklama, az önce verilen örneklerin anlamsal çerçevesini kavramak bakımından önemlidir. Burada belirtilmek istenen, "Pandemi sadece gelenekçiyi etkilemiştir." düşüncesi değildir. Nitekim böyle bir şey söylemek, insan olmanın sosyal varlık olmayla ilgisini baltalayacağı için geçersiz olur. Ancak geleneksel toplulukların diğer topluluklara göre bu süreçten daha fazla ve farklı şekillerde etkilendiği de bir gerçektir. Bu bağlamda, geleneksel yaşayan insan pandemi sürecinde kültürel davranışları uygulama noktasında önemli bir kriz süreci yaşamaktadır. Durum Türkiye özelinde değerlendirildiğinde, hem millii ${ }^{1}$ hem dini ${ }^{2}$ bayramlar hem de insanları aynı duygu etrafında toplayan diğer uygulama$\operatorname{lar}^{3}$ bu süreçten önemli oranda etkilenmiş ya yapılmamış ya da belli oranda yapılabilmiştir. Öncelikle bir ritüelin; toplulukları birleştirici, tamamlayıcı yönü düşünüldüğünde, kolektif hafızanın varlığını doğuran ve şekillendiren temel unsurların da bu dönemde yapılan ritüeller içerisinde olduğu anlaşılmaktadır. Çünkü insanları bir arada tutan gerçek bağlar kültürle ilgili olanlardır; onların paylaştıkları ülküler ve standartlardır (Benedict, 2005: 46). Bu görüşten hareketle bugün için kutlamaların/uygulamaların belli oranda yapılmasına karşın, sürecin devam etmesi halinde, bu kutlamaların/uygulamaların zamanla yapılamaması ilk olarak sosyal ilişkilere, sonrasında ise toplumsal bilinç yapısının temelini oluşturan biz bilincine önemli ölçüde zarar verecek ve kültürel davranışlar aracılığıyla sürdürülen

\footnotetext{
${ }^{1} 23$ Nisan Ulusal Egemenlik ve Çocuk Bayramı, 19 Mayıs Atatürk’ü Anma Gençlik ve Spor Bayramı

${ }^{2}$ Ramazan bayramı, Kurban bayramı

${ }^{3}$ Nevruz Bayramı
} 
milli, dini, toplumsal değerlerin önce zayıflamasına sonrasında zamanla- unutulmasına zemin hazırlayacaktır. Şimdilik sav olan bu düşünceyi ben ve biz bilincinin oluşum yapısı desteklemektedir. Bu noktada, ben bilincinin dışarıdan içeri doğru ilerleyen oluşumu dikkat çeker; özellikle oluşumundaki detay, etkileşim ve iletişime katılımı ve grubun kendisini algılayışını benimseme oranıdır, yani grubun biz kimliği, bireyin ben kimliğinden daha baskın bir şekilde varlık gösterir, sosyal var oluşun aktif olan bu yanı, ortak benliğin ya da biz bilincinin "taşıyıcısı" olan toplumun oluşumunu sağlar (Assmann, 2018: 140). Eğer bizin oluşum biçimi bu şekildeyse ve ben onu dışarıdan içeriye doğru kurulan bir etkileşim, iletişim içerisinde oluşturuyorsa bütün ve parça arsında kurulan iletişim formlarının kesilmesi aynı zamanda bütüne zarar vereceği için önemlidir.

Yukarıdaki düşünceler, aynı zamanda süreçte yapılamayan ve sürecin devam etmesi durumunda unutulması muhtemel sosyokültürel davranış kalıplarını da hatırlatmaktadır. Aslında bu durum, giriş bölümünde bahsedilmeye çalışılan endüstrileşme sonrası yaşanan değişime benzer bir değişimdir. Ancak olayın bir diğer tarafı kültür üretimi, onun ihtiyaç ile ilişkisi ve kültürel bir davranışın bir anda yok olmayacağıyla ilgili argümanlar içermesidir. Salgın hastalık döneminde birincil ihtiyaç, hayatta kalma, yaşamını devam ettirme arzusu olması nedeniyle bu duygu etrafında gelişen davranışlar diğer tüm davranışların önüne geçmektedir. Örneğin pandemi döneminde ve devam eden süreç içerisinde geçirilen dini bayramlarda yaşlıları ziyaret etme, onlara saygı gösterme, ellerini öpme gibi toplumsal kabuller etrafında gelişen birçok davranış, yerini yaşlıları sosyal izolasyona alma, onlarla uzaktan telefonla görüntülü görüşme gibi yeni davranış şekillerine dönüşmüştür. Bu örnekler; eskiden yapılan büyük aile toplantıları yerine çekirdek ailenin bir arada kalması, büyük ailenin uzaktan görüşme yöntemleriyle sürece dâhil edilmesi, söz, nişan, düğün gibi toplumsal uygulamaların ya ertelenmesi ya da ritüelsiz yapılması, geleneksel toplanma şekillerinin ortadan kalkması gibi sosyal hayatta somut bir şekilde yaşanan birçok değişimle artırılabilir. ${ }^{4}$ Tüm bunlar değerlendirildiğinde, öncelikle belirtilmesi gereken, sorunlara hızlı bir şekilde çözüm üretirken bilimden ve teknolojiden yararlanma, uygar zihnin ihtiyaca cevap verme şeklidir. Bu bağlamın verilecek tepki üzerindeki önemini vurgu-

\footnotetext{
${ }^{4}$ Ancak burada ayrıca eklenilmesi gereken şey, toplumun bütün katmanlarının aynı şekilde davranmadığı, bazı insanların tüm yasaklara rağmen eski sosyal hayatlarına devam ettiği gerek haberlerde gerek günlük hayatın akışı içerisinde görülmüştür. Bu durum toplulukların modernleşme süreciyle ilgili bilgi vermenin yanı sıra modernleşmenin olmazsa olmazı olan eğitim ile de ilgilidir.
} 
lar. Burada sosyal izolasyona rağmen sosyalleşme ve hayatını devam ettirme arzusu, bireye yeni davranış modelleri geliştirmekte ve bu davranışlar bir şekilde bağlamın imkânlarıyla sağlanmaktadır. Ancak bir torunun büyük anne ve dedesiyle bayramda ellerini öperek bayramlaşması yerine, dijital dünyanın imkânlarını kullanarak aile ilişkilerini sürdürmesi, eski kültürel davranışın yeni bir formda, yeni bir bağlamda icra edilmeye başladığını göstermektedir. Süreç nedeniyle değişen bu sosyokültürel davranışlar, sürecin devam edip etmeme durumuna göre yönünü belirleyecektir. Sürecin devam etmesi durumunda, bunlar, eski davranışlar yerine alternatif olarak üretilen ve dijital dünyanın imkânlarından faydalanan yeni bir kültürel bağlamın oluşacağıyla ilgili bir bilgi olarak değerlendirilebilir.

Öte yandan pandemi sürecinin yeni bir kültürel bağlamla kurulan ilişkisi durumu sınıfsal bir değerlendirmeye sürüklemektedir. Her ne kadar ülkelerde resmiyette sınıfsal bir sosyal izolasyon olmasa da gelişmiş, gelişmekte ve az gelişmiş ülke tanımlamaları, pandemi sürecinde yaşanan kültürel bağlamın hem kendisiyle hem de devam etmesi durumunda, geleceğiyle ilgili bilgi vermektedir. Düşünce detaylandırılırsa, öncelikle gelişmiş ülkelerin hızı bir şekilde dijitalleşeceği ve halklarının da bu hıza yetişeceği belirtilmelidir. Bunun aksine az gelişmiş ve gelişmekte olan ülkelerin teknolojik imkânları yeterince kullanamaması ve eğitimli diye tanımlanan, işgücüne aktif olarak katılan insan oranının, tarım ve hayvancılığı geleneksel yöntemlerle yaparak yaşamını idame ettiren ve "söz"e dayalı iletişim kuran insan oranına göre az olması, pandeminin devam etmesi durumunda bu ülkelerde yaşayan insanlar dijitalleşme sürecine tam olarak katılamayacaktır. Pandemi sürecinde bir zorunluluğa dönüşen dijitalleşme, az gelişmiş ya da gelişmekte olan ülke insanlarını insanlığın mecburi istikameti gereği kendilerini dışında tutamayacağı bir sürece sokmuştur. Kısıtlı da olsa teknolojiyi kullanan bu kitle, teknoloji insanının aksine bilgisini ritüel, ses, mimik, vücut ve dildeki ritim aracılığıyla aktarmaktadır. O kendini sözün dinamik yapısına bırakmıştır. Bu nedenle çalışmanın bu kısmında sözlü hareket eden ve konuşmaya önem veren bir kitlenin oluşturacağı kültürel bağlam için "sözelektronik" kavramı kullanılmıştır. Kavramla kastedilen bireyin söze dayalı kurduğu kültürel düzenini teknolojinin imkânlarıyla korumaya, aktarmaya çalışmasıdır. Bu asıında yeni bir kültürel bağlamdır. Bugün bile Instagram ve Facebook gibi tüm kültürel katmandan insanların kullandığı dijital platformlarda bu kullanıcılar bulunmakta ve bu alanlarda, birincil sözlü kültür çağını çağrıştırır biçimde; yani 
bireyci, bilişsel değil, daha çok dış dünyaya dönük, topluma ve olaylara daha açık ve daha az içe kapalı bir şekilde varlık göstermektedirler.

Pandemi döneminde değişikliğin yaşandığı bir diğer alan çalışma kültürüdür. Birincisi bu süreçte sağlık sektörü dışında kalan birçok alanda uzaktan çalışma sistemine geçilmiş, masa başı diye tanımlanan memurluk ve tam zamanlı çalışma kuralı hem kamu hem de özel kuruluşlarda devre dışı kalarak çalışma saatleri esnetilmiş ve çalışanlar iş yerinde yaptıkları işleri evlerinden sekiz-beş yerine tüm güne yayarak yürütmeye çalışmışlardır. Bu aşamadan sonra dünyaya eski gözle bakılmayacağının belki de bir işareti de burada saklı, şöyle ki bu süreçte, kişileri belli bir binada toplamanın iş performansı üzerindeki etkisi, binaların yapılma amacı sorgulanmalı, varılan sonuç: binalarda toplanmadan da işlerin ilerlediği şeklinde ise, süreç sonrasında yeni bir çalışma kültürü geliştirilmelidir. Düşünce biraz daha genişletilirse, ofiste bir işi yapan kişi ile aynı işi kendi evinde yol, yemek, kıyafet parası harcamadan yapan kişi, aynı donanıma sahipse ve yapılan iş aynı iş ise, binalara ve beraberindeki diğer ekonomik giderlere razı olmak ve eski sistemi devam ettirmeye çalışmak, bu noktadan sonra düzeni koruma adına katı bir muhafazakârlık olacaktır. ikinci olarak eğer artık iş kültürü eskisi gibi olmayacak ise işte burada -tıpkı yazının yukardaki bölümlerinde bahsi geçen eski kültürel alışkanlıkların mayalanması gibi- yeni alışkanlıklar anlamında bir mayalamanın söz konusu olduğunu belirtmek yanıltıcı olmayacaktır. Örneğin, masa başı çalışanlarının iş yerinde oluşturdukları bağlam -ki buna Dundes'in ifadesi ile halk denebilir- nitekim kendi içerisinde sosyal bir grubu, kültürel bir yapıyı oluşturmaktadır. Belirtilmeye çalışılan durumun kültürel davranış ile olan ilişkisi ise şu şekildedir. Bir işyerinde ortak bir faktör etrafında toplanan grup üyeleri hem sosyalleşmenin gereği hem de kültürel bazı alışkanlıklar nedeniyle birtakım toplanma alanları oluşturmaktadırlar. Bu toplanma mekânları, iş yeri kahvaltısı, çay sohbetleri, öğle yemekleri, bunlara bağlı geliştirilen dedikodu merkezli paylaşımlar, öğle saati alışverişleri, işe gidiş̧ ve dönüş davranışları hem bir kültür alanını kendi başına oluşturur hem de iletişimin söz ile sağlanan ve dış dünyaya daha dönük yanına vurgu yapar. Bu iletişimde hitabet sanatı jest, mimik; kimi zaman dokunma ile desteklenirken sosyal ilişkiler de güçlenmektedir. Ancak pandemi ile değişen iş kültürü beraberinde iş ortamında gelişen sosyokültürel davranışları sekteye uğratmıştır. Bu anlamda pandemi sürecinin devam etmesi iş kültüründe yaşanan değişimin devam etmesi anlamına gelecektir ki iş yerinde sağlanan kültürel iletişim, farklı noktalara taşınabilecektir. Benzer şekilde kafe, AVM, sinema, tiyatro gibi sosyalleşme alanları kendilerine yeni bağ- 
lamlar bulabilecek ve yüksek intimalle bu yeni bağlam dijital dünya üzerinden kurulmuş bir alandan oluşacaktır.

\section{Sonuç}

Teknolojinin gelişimiyle birlikte değişen paradigmalar, kültür kavramını, ona duyulan ilgiyi başka bir boyuta taşımış, gelenekçiyi, gelenek savunucularını panikletmiş ve bu panik, koruma içgüdüleriyle sonuçlanmıştır. Ancak kültürü koruma ve canlandırma adımları, belli noktalarda işlevsel olmalarının yanı sıra belli noktalarda amaçlarına ulaşamamaktadır. Asında bunun nedeni, atılan adımların eksikliği veya popüler bir yaklaşım olmasından daha ziyade kültürün bağlam ile olan ilişkisidir. Daha net bir şekilde ifade edilirse: kültür insanla beraber varlık gösteren bir unsurdur ve insan hangi çağdaysa ve kendisiyle beraber geçmişten ne kadarını getirdiyse o kadarını yaşatmaktadır. Bu cümlede ayrıntılanması gereken şey, kültürel seçimde insanlık istikametinin yönünün neyi seçip yaşantınıza dâhil edeceğiniz üzerindeki belirleyici bir rolü olduğudur. Bunun dışında kalan diğer unsurlar sadece kültürel miras olarak koruma altına alınabilir. Yani, bir kültürel öğenin/davranışın canlı olması ve süreklilik sağlaması, insan seçimine tabi olup yaşantıya dâhil edilmesiyle ilgilidir. Burada hemen ifade etmek gerekir ki bahsi geçen seçim, kültürel öğelerin/davranışların alt alta yazılarak ya da yan yana dizilerek yapılan bir seçim olmayacağı gibi tamamıyla rastgele yapılan bir seçim de değildir. Bu noktada herhangi bir kültürel davranışın unutulması veya yaşatılması tamamıyla o davranışın veya araç-gereç, imge vb. her şeyin; işlevsel, pratik ve benimseyicisine konfor alanı açıp açmaması ile ilgilidir.

Pandeminin kültürel boyuttaki etkileri değerlendirildiğinde, birkaç farklı yapı ortaya çıkar. Yukarıda belirtilmeye çalışanlardan hareketle pandemi sürecinde yaşanan ve kültürle ilintili olan ilk durum, toplulukların geçmişine dönük kültürel bir mayalanma yaşandığıdır. İkincisi, sürecin özellikle uzun süre devam etmesi durumunda- kimlik üzerinde yaratabileceği etkisidir. Üçüncüsü ise sürecin eski davranışlara alternatif davranış modelleri geliştirmesi nedeniyle bu davranışların sürecin devam etme süresine göre yeni kültürel edimler yaratacağı düşüncesidir. İkinci ve üçüncü durum birbirini belli oranlarda destekleyeceği için birlikte değerlendirilebilir. Ancak ilk durum kültürün sürekliliğiyle ilgili olduğu için ayrı değerlendirilmelidir. Bu noktada kültürün deneyim üzerine kurulu olduğu düşünülürse bilinen ya da daha önce tecrübe edilmiş herhangi bir kültürel davranışın canlanması ya da yeniden keşfedilmesi için gerekli bazı durumların olduğu ortaya çıkmaktadır. Bu noktada öncelikle, doğa insanı ile teknoloji insanının intiyaçlarının birbirinden farklı olduğu hatırlanmalı ve 
bu iki medeniyet dönemi arasındaki tarihi çizgi göz önünde bulundurulmalıdır, sonrasında ise bu tarihi çizgide kültürel deneyimlerin hayatta kalma ve sürekliliği tartışılmalıdır. Bu süreçte eğer eski ve yeni davranışın yer değiştirme sebebi bir mecburiyet sonucuysa -pandemi örneğinde olduğu gibi- değişim kaçınılmaz olacaktır, bundan sonra ise davranış değiş̧ikliğinin süresi devreye girmektedir. Bu süre yeni davranış biçiminin bilinçaltını etkileyeceği kadar uzun olması durumunda, başta mecburi bir durum sonrası geliş̧en davranış birçok şekilde kalıcı olacaktır. ${ }^{5}$ Burada, kültürün dinamik yapısının insan ve uygarlığın gelişimi ile olan ilişkisi ortaya çıkmaktadır. Öte yandan pandemi sürecinde geçmişe dönük kültürel mayalanma aynı zamanda kültürün var olma, canlanma biçimini göstermektedir. Yukarıda savunulan ile aynı noktada birleşen bu düşüncede; kültüre ait herhangi bir şeyin salt bir muhafazakârlıktan beslenmeyeceği, aynı zamanda bütünün küçücük parçalarında bile zaman zaman kendisini göstereceği, ortaya çıkma, canlanma ya da hayatta kalama şeklinin de ihtiyaç odaklı olduğu anlaşılmaktadır.

\section{Kaynakça}

Aslan, Recep (2020). "Tarihten Günümüze Epidemiler, Pandemiler ve Covid 19”. Göller Ayrıntı Dergisi, 85: 25-41.

Assmann, Jan (2018). Kütürel Bellek: Eski Yüksek Kültürlerde Yazı, Hatırlama ve Politik Kimlik. Çev. Ayşe Tekin. İstanbul: Ayrıntı Yayınları.

Benedict, Ruth (2018). Kültür Kalıpları. Çev. Mustafa Topal. İstanbul: iletişim Yayınevi.

Demir, Ayşegül (2018). "Bourdieu'nun Kavramları Doğrultusunda ilişkisel Olarak Fiziksel Engelliliğin Kültürel İnşası: Konak Örneği”. Journal of Social \& Humanities Sciences Research (JSHSR), 29: 3777- 3786.

Doğan, İsmail (2011). Eğitim Sosyolojisi. Ankara: Nobel Yayınları.

Eagleton, Terry (2019). Kültür. Çev. Berrak Göçer. İstanbul: Can Yayınları.

Kızıldağ, Hasan (2016). "Anakronik Bir Kahraman: 'Keloğlan Aramızda'”. The Journal of Academic Social Science Studies, 53: 447-458.

Malinowski, Bronislaw (2016). Bilimsel Bir Kültür Teorisi. Çev. Deniz Uludağ. Ankara: Doğubatı Yayınları.

Oğuz, M. Öcal (2018). Somut Olmayan Kültürel Miras Nedir? Ankara: Geleneksel Yayıncılık.

\footnotetext{
${ }^{5}$ Çalışmanın başından beri pandeminin süresi üzerinden ısrarla durulmasının en önemli nedeni, sürenin kültürel davranış üzerindeki belirleyici etkisidir.
} 
Oğuz, M. Öcal (2001). "Küreselleşme ve Ulusal Kalıt Kavramları Arasında Türk Halk Bilimi”, Milli Folklor, 50: 5-8.

Ong, Walter J. (2018). Sözlü ve Yazılı Kültür. Sözün Teknojileşmesi. Çev. Sema Postacıoğlu Banon. İstanbul: Metis Yayınları.

Özdemir, Nebi (2019). "Dördüncü Sanayi Devrimi ve Gelenek Kültürü”. 9. Milletlerarası Türk Halk Kültürü Kongresi (Ordu, 20-23 Kasım 2017). Ankara: Kültür ve Turizm Bakanlığı Yayınları, 207-241.

Özdemir, Mehmet Soner (2011). "Toplumsal Değişme ve Küreselleşme Bağlamında Eğitim ve Eğitim Programları: Kavramsal Bir Çözümleme”. Ahi Evran Üniversitesi Eğitim Fakültesi Dergisi, 12: 85-110.

URL-1: $\quad$ https://pazarlamasyon.com/mart-ayinda-hangi-urunlerinsatislari -artti-hangilerininki-azaldi/ (Erişim Tar.: 07.07.2020).

Yeşildal, Hatice (2012). "Toplumsal Değişme ve Küreselleşme”. Sosyolojiye Giriş. Ed. Nadir Suğur. Eskişehir: Anadolu Üniversitesi Yayınları. 